\title{
UWB Antenna with Single or Dual Band-Notched Characteristic for WLAN Band using Meandered Ground Stubs
}

\author{
Y. F. Weng ${ }^{1}$, W.J. Lu ${ }^{1,2}$, S. W. Cheung ${ }^{1}$ and T. I. Yuk ${ }^{1}$ \\ 1. Department of Electrical and Electronic Engineering, The University of Hong Kong, Hong Kong \\ 2. College of Communications and Information Engineering, Jiangsu Key Laboratory of Wireless Communications, \\ Nanjing University of Posts \& Telecom. Nanjing, Jiangsu, China \\ E-mail: [yfweng, wjlu, swcheung, tiyuk]@eee.hku.hk
}

\begin{abstract}
The paper proposes to use meandered grounded stubs to design single or dual band-notched planar-monopole antennas for ultrawide band (UWB) applications. The center-notch frequencies and notch bandwidths of the UWB antennas can be adjusted by using the dimensions of the meandered grounded stubs. Two prototype antennas are designed, fabricated and studied. One has a single band notch in the wireless area network (WLAN) band from $5.15 \mathrm{GHz}$ to $5.825 \mathrm{GHz}$ and the other one has two sets of dual-band notches at the lower WLAN band (5.15-5.35 GHz) and higher WLAN band (5.725-5.825 GHz). The band-notched characteristics, radiation patterns and peak gains of the antennas are studied using computer simulation and measurements.
\end{abstract}

Keywords - monopole antenna, ultrawideband (UWB) antenna, band notched, meandered ground stub.

\section{INTRODUCTION}

Since the US-FCC allocated the frequency band of 3.1-10.6 $\mathrm{GHz}$ for Ultra-wideband (UWB) communication systems in 2002 [1], studies on UWB technologies have been widely conducted in both the commercial and academic domains. In most UWB applications such as PCs, high-definition TVs and digital cameras etc., compact and low cost UWB antennas with non-dispersive, omnidirectional radiation pattern with relatively uniform gain are desirable. Planar antennas with the advantages of low-profile, ease fabrication on printed circuits board, and ease integration with other RF components, are more favorable to the traditional 3-D antennas for compact UWB applications.

In the design of antennas for UWB applications, there are important challenges. For example, in the allocated frequency band for UWB applications, there are already several other existing communication systems such as the IEEE 802.11a WLAN which has the lower frequency band of 5.15-5.35 GHz and higher frequency band of $5.725-5.825 \mathrm{GHz}$ in the US [2]. These systems may potentially interfere with the UWB systems. Band-stop filters can be used to suppress the interference problems, but this will increase the cost and system complexity and require more space when integrated with other microwave circuits. One possible solution for this problem is to design the UWB antennas with band-notched characteristics. Different design methods have been proposed to implement the band- notched characteristic for UWB planar monopole antennas [312], e.g. using parasitic elements [4], folded strips [5], splitring resonator (SRR) [6], quarter wavelength tuning stub [7], resonated cell in microstrip line or coplanar waveguide (CPW) [8] and fractal structure [9]. The most popular method is to etch different kinds of half or quarter wavelength slots or stubs, i.e. U-shaped [10-11], V-shaped [12], and hat-shaped slot [13] etc. on the antennas. Since the current of a planar-monopole antenna mainly distributes on the edges of the radiators and ground, it is more effective to place the slots or stubs along these edges. However, for the half or quarter wavelength resonators, it is difficult to place them on the compact UWB antenna to achieve dual or multiple band-notched function.

In this paper, we propose to use meandered ground stubs to realize the band-notched characteristic in the compact UWB monopole antenna. Two UWB antennas with single or dual band-notched characteristics are studied using the computer simulation tool CST MWS 2009 [14] and the Satimo Starlab measurement system [15]. For the UWB antenna with single band-notched characteristic at $5.5 \mathrm{GHz}$, a pair of meandered ground stubs, each having a size of $0.0715 \lambda \times 0.042 \lambda$, is used to achieve a Voltage-Standing-Wave Ratio (VSWR) $\leqslant 2$ for the operating frequency range from $2.52 \mathrm{GHz}$ to over $12 \mathrm{GHz}$. For the UWB antenna with dual band-notched characteristic, two pairs of meandered ground stubs with different sizes, $0.057 \lambda \times 0.051 \lambda$ for $5.25 \mathrm{GHz}$ and $0.057 \lambda \times 0.045 \lambda$ for 5.775 $\mathrm{GHz}$, are employed to filter the higher and lower frequency bands in the WLAN band. The simulated and measured results show that the antenna has an operating frequency range from $2.57 \mathrm{GHz}$ to over $11.05 \mathrm{GHz}$ with VSWR $\leqslant 2$ which fully satisfies the requirement for UWB applications.

\section{ANTENNA DESIGN}

\section{Structure of the single band-notched UWB antenna}

In our UWB antenna design, we propose to use the planarmonopole technology to achieve a compact size for applications in wireless devices. The single band-notch UWB antenna consists of an elliptical radiator fed by a $50-\Omega$ microstrip line and a rectangular ground below the substrate with two symmetric meandered open-circuit ground stubs etched at the upper edge of the ground plane. Figure 1 shows the layout of our design which is fabricated on a Rogers PCB, $\mathrm{RO} 4350 \mathrm{~B}$, with a transverse dimension of $30 \mathrm{~mm} \times 39.3 \mathrm{~mm}$, a 
relative dielectric constant $\varepsilon_{r}=3.48$, a thickness $0.762 \mathrm{~mm}$ and a loss tangent 0.0037 for the substrate. The width of the microstrip line changes gradually from $w_{1}=1.73 \mathrm{~mm}$ to $w_{2}=$ $0.6 \mathrm{~mm}$ to achieve good impedance matching. The distance between the elliptical radiator and the upper edge of ground, gap, is also critical for impedance matching and so has been optimized to be $0.3 \mathrm{~mm}$. Detailed dimensions of the single band-notched antenna are listed in Table 1.

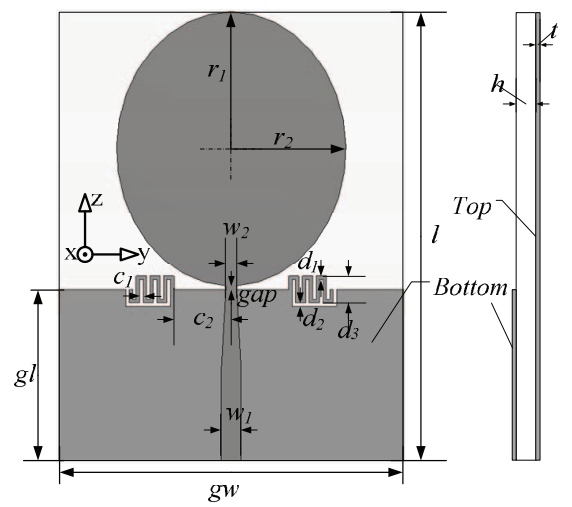

(a)

(b)

Fig. 1 (a) Layout and (b) side view of the single band-notched UWB antenna.

TABLE I. SINGLE BAND-NotCHED ANTENNA DIMENSIONS

\begin{tabular}{cccc}
\hline Parameter & Value $(\mathbf{m m})$ & Parameter & Value $(\mathbf{m m})$ \\
\hline$g l$ & 15 & $w_{1}$ & 1.73 \\
$g w$ & 30 & $w_{2}$ & 0.6 \\
$l$ & 39.3 & $d_{1}$ & 0.3 \\
$r_{1}$ & 12 & $d_{2}$ & 0.3 \\
$r_{2}$ & 9 & $d_{3}$ & 2.3 \\
$t$ & 0.035 & $c_{1}$ & 0.3 \\
$H$ & 0.762 & $c_{2}$ & 5 \\
$g a p$ & 0.3 & & \\
\hline
\end{tabular}

\section{Parametric study of single band-notched UWB antenna}

To better understand how the dimensions of the meandered ground stubs affect the center frequency and bandwidth of the notched band, a parametric study of the single band-notched UWB antenna has been conducted using computer simulation. Results have shown that the proposed band-notch structure using the meandered stubs acts like a resonator. At resonance, it prevents signal from passing through it. The width $d_{l}$ and length $d_{3}$ of the stubs in Fig. 1(a) determine the inductance of the resonator. The distances, $d_{2}$ and $c_{1}$, between the stub and ground and between the meandered stubs, respectively, determine the capacitance of the resonator.

Simulation results on the VSWR with different values of $d_{3}$ and $c_{2}$ using CST MWS 2009 are shown in Figs. 2 and 3, respectively. It can be seen that the resonant frequency can be adjusted using $d_{3}$, yet the VSWR values in the rest of the UWB band remain about the same. This property provides the designers with a great freedom to select the notched-band frequency for the antennas.

Figure 3 shows that the bandwidth of the notched band can be adjusted easily by varing $c_{2}$ with other parameters remaining constant, yet the center frequency of the notch band is almost unchanged.

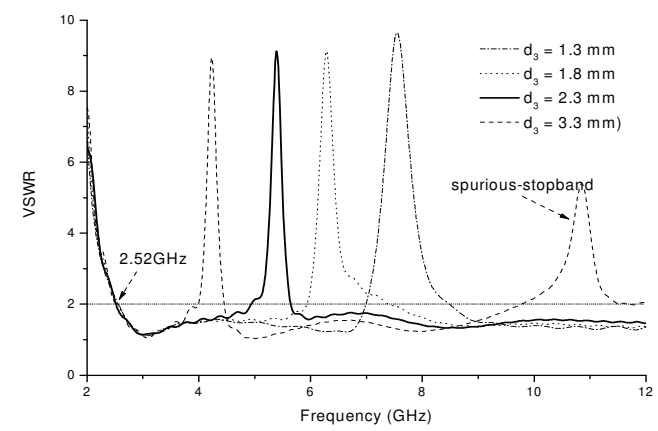

Fig. 2 VSWR for different values of $d_{3}$, with $d_{1}=d_{2}=c_{3}=0.3 \mathrm{~mm}$ and $c_{2}=5 \mathrm{~mm}$.

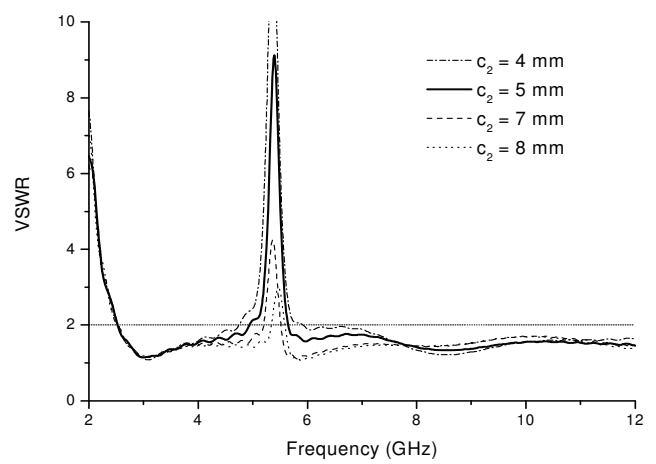

Fig. 3 VSWR for different values of $c_{2}$, with $d_{1}=d_{2}=c_{3}=0.3 \mathrm{~mm}$ and $d_{3}=2.3 \mathrm{~mm}$.

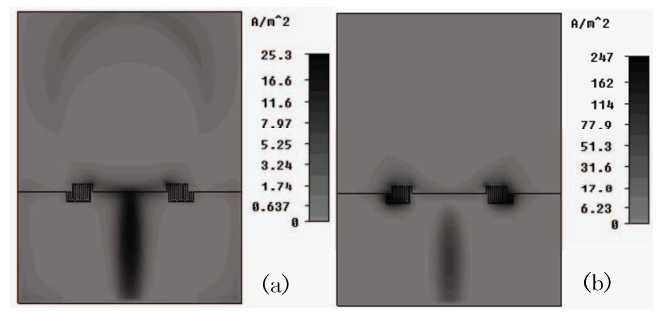

Fig. 4 Surface current distribution of single band-notched antenna at (a) 3.5 $\mathrm{GHz}$ and (b) $5.5 \mathrm{GHz}$.

Figures 4(a) and 4(b) show the surface current distribution of the single band-notched antenna at $3.5 \mathrm{GHz}$ and $5.5 \mathrm{GHz}$, respectively. At $3.5 \mathrm{GHz}$, Fig. 4(a) shows that majority of the current flows from the microstrip line to the radiator and will finally radiate to the free space. However, at $5.5 \mathrm{GHz}$, the energy is confined in the meandered ground stubs and much more than those in the main radiator of the antenna, so it does not get radiated.

\section{Dual band-notched UWB antenna}

The main challenge in the dual band-notched design is the narrow bandwidths $(100 \mathrm{MHz}$ in the higher WLAN band and $200 \mathrm{MHz}$ in the lower WLAN band) of the notched bands which have a relatively small gap of $375 \mathrm{MHz}$ in between. Our proposed dual band-notched UWB antenna makes use of the results obtained in our design for the single band-notched UWB antenna explained previously, i.e. the center frequency and bandwidth of the notch can be adjusted by using $d_{3}$ and 
$c_{2}$. In this design, two different sizes of meandered ground stubs are put in serious along the upper edge of the ground plane, as shown in Fig. 4. The detailed dimensions of the two stubs are listed in Table 2.

TABLE II. SINGLE BAND-NotCHED ANTENNA DIMENSIONS

\begin{tabular}{cccc}
\hline $\begin{array}{c}\text { Parameter (upper } \\
\text { WLAN Band) }\end{array}$ & Value(mm) & $\begin{array}{c}\text { Parameter (lower } \\
\text { WLAN Band) }\end{array}$ & Value $($ mm) \\
\hline$d_{1}$ & 0.25 & $d_{1}$ & 0.25 \\
$d_{2}$ & 0.25 & $d_{2}$ & 0.25 \\
$d_{3}$ & 2.6 & $d_{3}$ & 2.9 \\
$c_{1}$ & 0.25 & $c_{1}$ & 0.25 \\
$c_{2}$ & 8.5 & $c_{2}$ & 5 \\
\hline
\end{tabular}

\section{RESULTS AND DISCUSSIONS}

The two antenna prototypes, with both single and dual band-notched characteristics, have been fabricated using Rogers PCBs, RO4305B, as shown in Fig. 5. The VSWR and peak gain across the UWB band, and the radiation patterns at $3.5 \mathrm{GHz}, 7 \mathrm{GHz}$ and $9 \mathrm{GHz}$ have been simulated using CST MWS 2009 and measured by using the Satimo Starlab measurement system.

The simulated and measured VSWRs of the single and dual band-notched antennas are shown in Fig. 6. For clarity, the VSWR of the antennas from 4.5 to $6.5 \mathrm{GHz}$ are enlarged and shown separately in the same figure. It can be seen that the VSWR is substantially higher in the desired WLAN bands. The detailed parameters of the band notches are listed in Table 3 . These results show that the two antennas can operate from 2.52 $\mathrm{GHz}$ to over $12 \mathrm{GHz}$ and from $2.57 \mathrm{GHz}$ to $11.05 \mathrm{GHz}$ with VSWR $\leqslant 2$ which fully satisfies the UWB requirement.

TABLE III. BAND-NOTCHES WHEN VSWRS ARE 2 AND 2.5

\begin{tabular}{lcc}
\hline \multicolumn{1}{c}{ Notched Band } & VSWR = 2 & VSWR = 2.5 \\
\hline Simulated, whole WLAN band & $5.08-5.89 \mathrm{GHz}$ & $5.23-5.77 \mathrm{GHz}$ \\
Measured, whole WLAN band & $5.06-5.91 \mathrm{GHz}$ & $5.19-5.82 \mathrm{GHz}$ \\
Simulated, upper WLAN band & $5.66-5.90 \mathrm{GHz}$ & $5.71-5.86 \mathrm{GHz}$ \\
Measured, upper WLAN band & $5.62-5.93 \mathrm{GHz}$ & $5.70-5.87 \mathrm{GHz}$ \\
Simulated, lower WLAN band & $4.98-5.41 \mathrm{GHz}$ & $5.11-5.38 \mathrm{GHz}$ \\
Measured, lower WLAN band & $5.01-5.41 \mathrm{GHz}$ & $5.12-5.34 \mathrm{GHz}$ \\
\hline
\end{tabular}

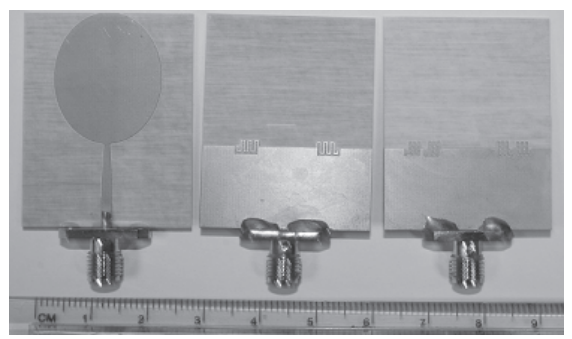

Fig. 5 Photograph of proposed single and dual band-notched antennas.

The simulated and measured radiation patterns of the antennas at $3.5 \mathrm{GHz}$ and $9 \mathrm{GHz}$ in two principle planes, $\mathrm{x}-\mathrm{z}$ and $x-y$ planes, are shown in Fig. 7. It can be seen that the antennas have approximately omnidirectional radiation patterns in $\mathrm{x}-\mathrm{y}$ plane. The $\mathrm{x}-\mathrm{z}$ plane patterns show two nulls at $\mathrm{z}$ direction, which are similar to that of typical monopole antennas.

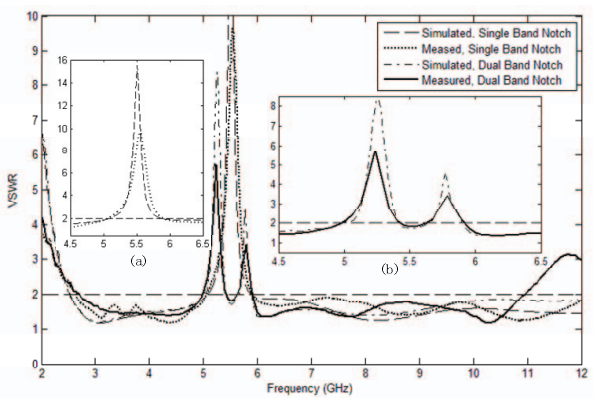

Fig. 6 Simulated and measured VSWR of single and dual band-notched antennas. VSWR of (a) single band-notched and (b) dual band-notched antennas from 4.5 to $6.5 \mathrm{GHz}$.
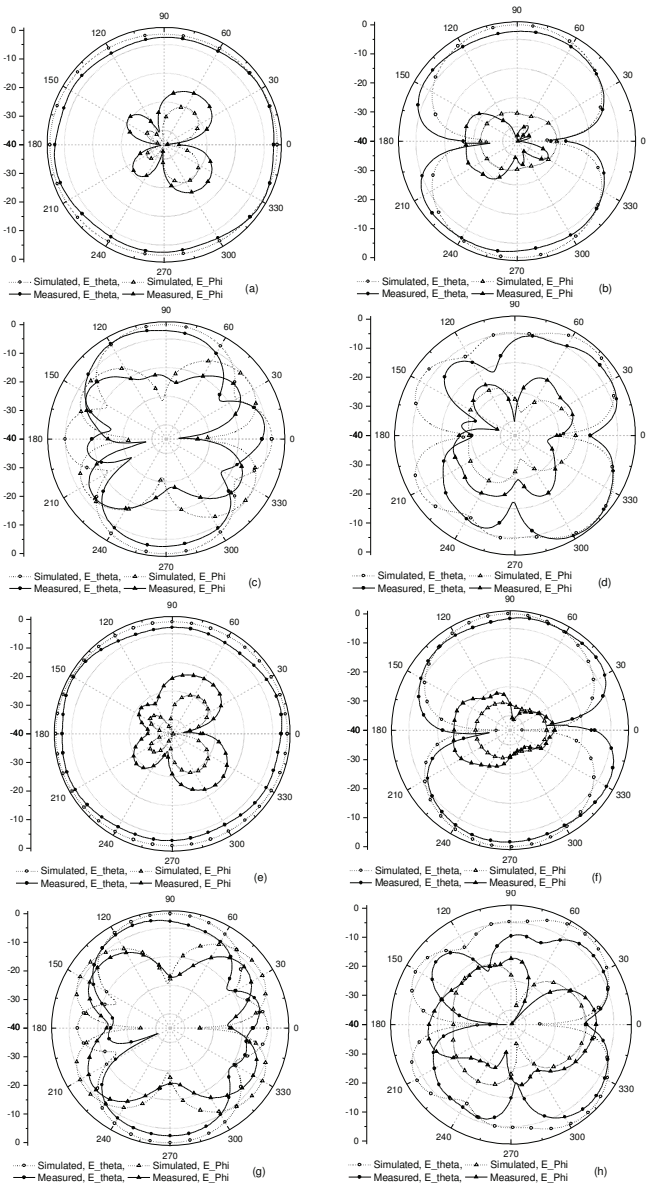

Fig. 7 Simulated and Measured radiation patterns. (a) $3.5 \mathrm{GHz}$ in $x-y$ plane for single band-notched antenna; (b) $3.5 \mathrm{GHz}$ in $\mathrm{x}-\mathrm{z}$ plane for single band-notched antenna; (c) $9 \mathrm{GHz}$ in $\mathrm{x}-\mathrm{y}$ plane for single band-notched antenna; and (d) 9 $\mathrm{GHz}$ in $\mathrm{x}-\mathrm{z}$ plane for single band-notched antenna; (e) $3.5 \mathrm{GHz}$ in $\mathrm{x}-\mathrm{y}$ plane for dual band-notched antenna; (f) $3.5 \mathrm{GHz}$ in $\mathrm{x}-\mathrm{z}$ plane for dual band-notched antenna; (g) $9 \mathrm{GHz}$ in x-y plane for dual band-notched antenna; and (h) $9 \mathrm{GHz}$ in $\mathrm{x}-\mathrm{z}$ plane for dual band-notched antenna.

The measured peak gains of the antenna with single and dual band notches are shown in Fig. 8. It is observed that the average antenna gain is about $3 \mathrm{dBi}$ over most of the operating 
frequency range. While at the notched band, a significant gain and radiation efficiency reduction can be seen. For the single band-notched case, the antenna gain is reduced to about $-7 \mathrm{dBi}$ and the radiation efficiency is lower than $20 \%$. For the dual band-notched case, the antenna gain is reduced to $-6 \mathrm{dBi}$ and -2 $\mathrm{dBi}$ and the radiation efficiency is reduced to below $20 \%$ and below $45 \%$, respectively. These phenomena indicate that by introducing one or more pairs of meandered ground stubs, a single or dual band-notched characteristic can be achieved.

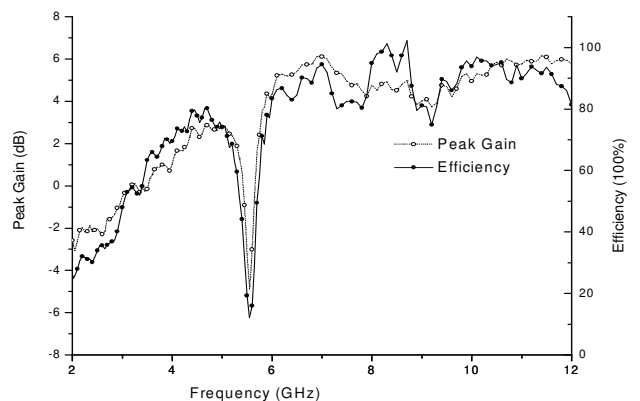

(a)

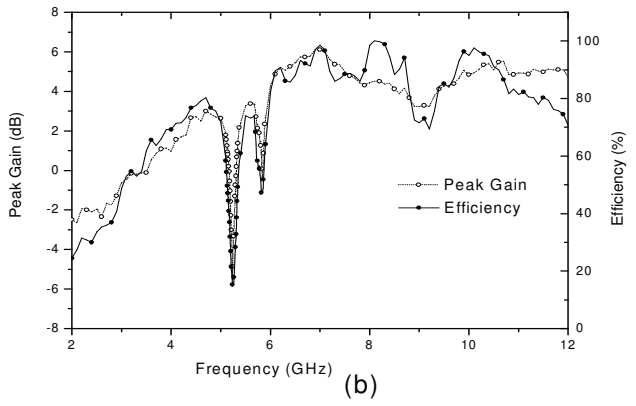

Fig. 8 Simulated and measured peak gain and efficiency a) with single band notch and $b$ ) dual band notches

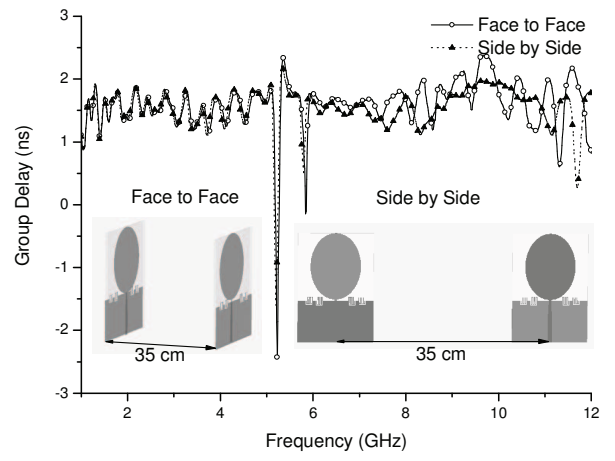

Fig.9 Measured group delays between pair of dual band-notched antennas

Finally, the group delay characteristics between a pair of dual band-notched antennas have also been measured. In the experiment, the distance between the two antennas was $35 \mathrm{~cm}$. Without loss of generality, two special cases, i.e., with the antennas placed face-to-face and side-by-side at different azimuth angle on the $x-y$ plane. The results are showed in Fig. 9 , indicating that, in both cases, the group delay is about $1.5 \mathrm{~ns}$ across the frequency band except in the notched bands. Due to the narrow band resonator, the group delays at the notched lower and higher WLAN bands vary drastically to $-2.5 \mathrm{~ns}$ and $0.25 \mathrm{~ns}$, respectively. For the rest of the frequency band, the group delay characteristics is relatively flat, indicating that that the antennas have good linear transmission performances and so could be useful for multi-band UWB or impulse UWB radios applications.

\section{CONCLUSIONS}

In this paper, meandered ground stubs have been proposed to implement the band-notched characteristics of planarmonopole antennas for UWB applications. Two novel bandnotched monopole-antennas using meandered ground stubs to realize the single and dual band-notched characteristics have been designed and studied using computer simulation and measurement. Results have shown that these antennas have approximately omnidirectional radiation patterns with good band notched performances. The measured group delay characteristics of the dual band antenna are relatively flat, implying that the antenna is good for multi-band UWB or impulse UWB radios applications.

\section{REFERENCES}

[1] "Federal Communications Commission Revision of Part 15 of the Commission's Rules Regarding Ultra-Wideband Transmission Systems," FCC, 2002, First Report and Order FCC, 02.V48.

[2] Availanle on: http://www.fcc.gov/pshs/techtopics/techtopics10.html .

[3] Schantz, Hans, Glenn Wolenec, Edward (Mike) Myszka, "Frequency notched UWB antennas," IEEE Conference on Ultra Wideband Systems and Technologies. Reston, Virginia, Nov, 2003.

[4] K. Kim, Y. Cho, S. Hwang, and S. Park, "Band-notched UWB planar monopole antenna with two parasitic patches," Electron. Lett., vol. 41, no. 14, pp. 783-785, Jul. 2005.

[5] T. G. Ma and S. J. Wu, "Ultrawideband band-notched folded strip monopole antenna," IEEE Trans. Antennas Propag., vol. 55, no. 9, pp. 2473-2479, Sep. 2007

[6] J. Kim, C. S. Cho and J. W. Lee, "5.2 GHz notched ultra-wideband antenna using slot-type SRR,” Electron. Lett., vol. 42, no. 6, pp. 315316, Mar. 2006

[7] A. Kerkhoff and H. Ling, "Design of a planar monopole antenna for use with ultra-wideband (UWB) having a band-notched characteristic," in IEEE AP/S Int. Symp. Dig., 2003, vol. 1, pp. 830-833.

[8] S.W. Qu, J.L. Li and Q. Xue, "A Band-Notched Ultrawideband Printed Monopole Antenna," IEEE Antennas and Wireless Progag Lett, vol. 5, pp. 495-498, 2006

[9] W. J. Lui, C. H. Cheng, Y. Cheng, and H. Zhu, "Frequency notched ultra-wideband microstrip slot antenna with fractal tuning stub," Electron. Lett., vol. 41, no.6, pp.294-296, Mar., 2005.

[10] Y.J. Cho, K.H. Kim, D.H. Choi, S.S. Lee and S.O. Park, "A miniature UWB planar monopole antenna with $5 \mathrm{GHz}$ band-rejection filter," IEEE Trans. Antennas and Propag, vol. 54, issue 5, pp. 1453-1460, Oct, 2005.

[11] W.S. Lee, W. G. Kim, and J.Y. Yu, "Multiple band-notch planar monopole antenna for multiband wireless system," IEEE Microw. Wireless Compon. Lett., vol.15, no.9, pp.576-578, Sep. 2005.

[12] Y. Kim and D.-H. Kwon, "CPW-fed planar ultra wideband antenna having a frequency band notch function," Electron. Lett., vol.40, no.7, pp.403-405, Apr.2004.

[13] J. N. Lee, J. K. Park, and S. S. Choi, "Design of a compact frequency notched UWB slot antenna," Microw. Opt. Technol. Lett., vol. 48, no.1, pp.105-107, Jan. 2006.

[14] Availanle on: http://www.cst.com.

[15] Available on: http://www.satimo.fr/eng/index.php?categoryid=141 